\title{
Electrochemical behaviour of ZrTi alloys in artificial physiological solution simulating in vitro inflammatory conditions
}

\author{
J. Izquierdo ${ }^{1}$ G. Bolat ${ }^{2}$, D. Mareci², C. Munteanu ${ }^{3}$, S. González ${ }^{1,4}$, R.M. Souto ${ }^{1,4}$
}

${ }^{1}$ Department of Physical Chemistry, University of La Laguna, E-38071 La Laguna (Tenerife), Spain

2 “Gheorghe Asachi” Technical University of Iasi, Faculty of Chemical Engineering and Environmental Protection, 73 Prof. Dr. Doc. D. Mangeron St., 700050, Iasi, Romania

3 “Gheorghe Asachi” Technical University of Iasi, Faculty of Mechanical Engineering, 61-63 Prof. Dr. Doc. D. Mangeron St., 700050, Iasi, Romania

${ }^{4}$ Instituto Universitario de Materiales y Nanotecnologías, University of La Laguna, E-38200 La Laguna, Tenerife, Canary Islands, Spain

\begin{abstract}
ZrTi alloys in artificial physiological solution simulating in vitro inflammatory conditions were investigated for biomedical application. Effect of surface treatment on the corrosion resistance of Zr5Ti, Zr25Ti, and Zr45Ti in acidified Ringer's solution $(\mathrm{pH}=3)$ at $25^{\circ} \mathrm{C}$ was evaluated using electrochemical impedance spectroscopy, potentiodynamic polarization curves, and scanning electrochemical microscopy. Thermal oxidation in air at $500{ }^{\circ} \mathrm{C}$ produces materials with high in vitro corrosion resistance to acidic environments. Higher impedance values related to passivity were observed for oxidized ZrTi alloys compared to as-cast materials. SECM reveals thermal oxidation produced more compact and electrically insulating oxide films.
\end{abstract}

Keywords: Zirconium-titanium alloys; Biomaterials; Surface treatment; Simulated physiological solution; Electrochemical techniques; Corrosion resistance. 


\section{Introduction}

Metallic biomaterials play an essential role in repair or replacement of diseased or damaged bone tissue. The metals are more suitable for load-bearing applications compared with ceramics or polymeric materials because they combine high mechanical strength with fracture toughness [1-4]. In recent years, surgical alloys are investigated with a strong emphasis on their corrosion behaviour and biocompatibility due to reports of metallosis and necrosis [5-7]. Particularly, corrosion resistance is very important due to the hostile environments they experience in service. Different parts of the human body present different $\mathrm{pH}$ and oxygen concentration [8]. Ideally, metallic materials should be inert for implant application, but they react with components in the organic fluids, and they experience electrochemical activity to some extent. Although metals and alloys spontaneously undergo oxidation in air and aqueous environments, certain metals and alloys can form adherent and tenacious oxide films on their surface, which render them passive. Yet, this passive regime is actually a dynamic state, and passivity breakdown and reforming occurs [9], though in degrees that greatly vary between the different materials [10,11]. Additionally, for a given material, this transient behaviour is also influenced the composition of the environment [12]. Metal release into the surrounding tissues may be the outcome from those transient passivity breakdowns [11]. Implant corrosion caused by the reaction with body fluids and tissues seems to affect the fatigue life as well [13]. Furthermore, immediately after implantation, fibrin and chloride ions surround the metallic biomaterials, with the subsequent decrease of the local $\mathrm{pH}$ [14]. Acidification is harmful to the stability of the passive regime [15-17]. In summary, for medical implant materials, it is important to minimize corrosion and the release of the metal ions [18]. In vitro evaluation of corrosion behaviour constitutes the first stage in the procedure to establish the successful applicability of metallic biomaterials [19]. The corrosion of a metal implant in the human body is primarily driven by electrochemical reactions. Consequently, electrochemical methods can be employed to evaluate the corrosion resistance of new implant alloys.

Titanium and its alloys present a high corrosion resistance under severely corrosive environments [20], and they exhibit excellent biocompatibility and osseointegration characteristics [21]. Because of its adequate mechanical properties, high corrosion resistance and excellent hemocompatibility, zirconium is believed to be an ideal alloying metal for titanium in biomedical applications [22-25]. The good corrosion resistance of zirconium, titanium, and their alloys is mainly due to a very good stable oxide grown spontaneously on their surface [26,27]. Yet, their potential use as 
biomaterials is a matter of concern due to the rather high susceptibility to pitting corrosion of the oxide films spontaneously developed on zirconium-rich alloys during exposure to halide-containing electrolytes [25]. Localized corrosion can be very harmful, because it produces a corrosive attack that penetrates inside the matrix of the material, whereas most of the surface remains unaltered during long exposures. Higher corrosion resistance materials is thus demanded, and surface modification techniques are required to obtain surface layers of enhanced stability against localized corrosion processes. Indeed, some recent publications have reported the enhancement of the corrosion resistance of the oxide films formed on some titanium-based alloys due to chemical surface modification techniques [28,29]. In a recent work, we explored the effect of thermal oxidation in air of ZrTi alloys, leading to the observation that such treatment produced an improvement in their corrosion resistance during exposure to mild neutral saline conditions [30]. Thus, surface modification of ZrTi alloys can provide a route to obtain ZrTi materials with sufficient chemical stability to be considered as effective new biomaterials for bone and teeth replacement or restoration. In this work, we further investigate the corrosion resistance of thermally oxidized ZrTi alloys to cover the aggressive corrosive conditions that arise in the body as result of surgical procedures, typically related to inflammatory processes. Thermal oxidation at $500{ }^{\circ} \mathrm{C}$ was applied to Zr5Ti, Zr25Ti and Zr45Ti alloys with the aim to enhance the stability of the passive films formed on their surface. The electrochemical behaviour of both untreated and thermally oxidized ZrTi alloys was investigated in acidified Ringer's physiological solution of $\mathrm{pH}=3$ at ambient temperature using a powerful combination of electrochemical and microelectrochemical techniques.

\section{Materials and methods}

\subsection{Materials}

Three ZrTi alloys were fabricated by electron beam melting method. The melting procedure was repeated three times in order to obtain chemically homogenized alloys. The chemical compositions have been determined by Energy Dispersive X-ray analysis (EDX), using a scanning electron microscope Quanta 3D (model AL99/D8229) equipped with an EDX detector. Chemical compositions (wt.\%) of the alloys are as follows: Zr-4.3\%Ti-0.3\%Nb-0.3\%Mo (named Zr5Ti), Zr-23.8\%Ti-0.4Nb\%Zr-0.7\%Mo (named Zr25Ti), and Zr-43.9\%Ti-0.4\%Nb-0.5\%Mo (named Zr45Ti). Discs of $0.28 \mathrm{~cm}^{2}$ area were cut 
from the ingots. The surface of the specimens were ground with SiC abrasive paper up to 2000 grit, followed by polishing with $1 \mu \mathrm{m}$ alumina suspension, and then cleaned ultrasonically in ethyl alcohol and in deionised water, and finally dried under a cold air stream. After preparing the surface, selected specimens were treated by thermal oxidation: the samples were oxidized in air atmosphere in an oven for $2 \mathrm{~h}$ at $500{ }^{\circ} \mathrm{C}$.

\subsection{Electrochemical measurements}

Potentiodynamic polarization and electrochemical impedance tests were performed using a potentiostat (PARSTAT 4000, Princeton Applied Research, NJ, USA) controlled by a computer for data acquisition using specific software (VersaStudio, PAR, USA). A glass corrosion cell, which was filled with acidified Ringer's solution at $\mathrm{pH}=3$, was employed. $\mathrm{pH}$ was adjusted using controlled additions of $\mathrm{HCl}$ solution. The sample was mounted in a polytetrafluoroethylene sample holder so that the exposed surface was one circular side of the disc. A saturated calomel electrode was used as the reference electrode, and a platinum coil as the counter electrode. The temperature of the electrochemical cell was maintained at $25^{\circ} \mathrm{C}$. Upon immersion, the samples were left unpolarized for $1 \mathrm{~h}$ to spontaneously attain their open circuit potential (OCP) in the electrolyte. Electrochemical impedance spectroscopy (EIS) measurements were carried out subsequently at the OCP with an AC amplitude of $10 \mathrm{mV}$, and a scan frequency ranging from $100 \mathrm{kHz}$ to $1 \mathrm{mHz}$. Two electrochemical impedance spectra were determined at different times since the specimen was immersed in the modified Ringer's solution, namely 1 hour and 1 day. EIS data were analyzed in terms of equivalent circuits (EC) using ZSimpWin 3.22 software [31]. After completing the EIS measurements, potentiodynamic polarization curves were recorded from -0.8 to $+1.0 \mathrm{~V}_{\text {SCE }}$ using a scan rate of $0.5 \mathrm{mV} \mathrm{s}^{-1}$. Electrochemical tests were repeated three times to verify the reproducibility of the results.

Scanning electrochemical microscopy (SECM) was performed using Sensolytics SECM (Bochum, Germany). A $10 \mu \mathrm{m}$ diameter Pt microelectrode, Ag/AgCl (3M KCl), and a Pt strip were used as working, reference and auxiliary electrodes, respectively. $0.5 \mathrm{mM}$ ferrocene-methanol was added to the acidified Ringer's solution to act as redox mediator at the tip. The distance between the tip and the substrate was fixed at $10 \mu \mathrm{m}$ after measuring the $z$-approach curves towards the surface. 3D images in constant height mode were obtained by scanning the tip in the $x-y$ plane at $25 \mu \mathrm{m} \mathrm{s}^{-1}$, and recording the tip current as a function of tip location. An area of $250 \mu \mathrm{m}$ x $250 \mu \mathrm{m}$ was examined in each specimen. 


\subsection{Surface characterization}

A scanning electron microscope (SEM) Quanta 200 (FEI, Hillsboro, OR, USA) operated at an accelerating voltage of $20 \mathrm{kV}$ was employed to characterize any morphological changes produced to the specimens after anodic polarization treatment in acidified Ringer's solution at $25^{\circ} \mathrm{C}$.

\section{Results and discussion}

Corrosion resistance of zirconium-titanium alloys is due to the formation of a protective passive layer [25]. The surface oxide layer acts as a dielectric barrier hindering metal release. The stronger is the passive layer, greater corrosion resistance is achieved. Impedance spectra of the three untreated ZrTi alloys in acidified Ringer's solution at the ЕосP are presented as Bode phase and Bode magnitude plots in Figure 1. They were measured either 1 hour (A) or 1 day (B) after exposure of the specimens to the simulated artificial solution. Two time constants were clearly found in all cases, one corresponding to the thin native oxide film, and the other to the charge transfer process at the surfaces of the alloys. Quantitative data to assist the interpretation of the EIS results can be obtained by using an electrical analogue representing the physicochemical processes occurring at the alloys. Impedance parameters were then determined by adopting the equivalent circuit (EC) presented in Figure 2. The model consisted of two parallel constant phase elements/resistor pairs, $Q_{1} / R_{1}$ and $Q_{2} / R_{2}$, where underscripts 1 and 2 designate the time constants found in the low and the high frequency ranges, respectively. Good agreement between the measured spectra (discrete points) and the fitted spectra (solid lines) is observed in Figure 1, and Table 1 gives the values of the calculated impedance parameters. Comparison of the spectra measured for each material at the two exposures illustrates that the corrosion resistance of the materials slowly decrease with the elapsed time in the acidic Ringer's solution. Next, the impedance determined for the Zr45Ti alloy is higher than those of the Zr25Ti and Zr5Ti alloys.

Figure 3 shows the Bode plots from the thermally oxidized ZrTi alloys measured after 1 hour and 1 day exposure to acidified Ringer's solution. The two time constant model of the alloy/oxide/solution interface also held in this case, and good quality fits were obtained. The values of the corresponding impedance parameters are listed in Table 2. Increase of the impedance modulus for the oxidized specimens compared to those untreated indicate an increase in corrosion resistance of the resulting oxide films. Meanwhile, the phase angle shifted to values ca. $-90^{\circ}$ in a wider frequency range at both 
intermediate and low frequency ranges for oxidized Zr45Ti, which is an indication of more stable passive films. Indeed, the values of both $R_{1}$ and $R_{2}$ are bigger for oxidized Zr45Ti than for the untreated alloy, this increase being especially relevant in the case of $R_{2}$, that is almost 10 times bigger. Therefore, the improved corrosion resistance of the oxidized alloy arises mostly from the growth of the inner oxide layer directly attached to the underlying metal, and this was accompanied by a slightly less porous outer oxide layer leading to the obtention of a sealed barrier to protect the metal.

The oxidation process also produces an improvement on the corrosion resistance of the other two alloys. Though the beneficial effect arises almost exclusively from the thin inner oxide layer in this case (i.e., higher values are only observed for $R_{2}$ ), whereas a more porous outer layer is observed. Indeed, the Bode phase plots show a poor dielectric behaviour for these materials as indicated by the smaller phase angles occurring in the intermediate and low frequency ranges. Therefore, they are expected to resist the aggressive attack of the simulated physiological solution for shorter exposures.

Polarization curves recorded for untreated and treated ZrTi alloys are presented in Figure 4. None of the specimens displayed an active region in the curves because of the passive oxide layer formed on their surface. The corrosion potential $\left(E_{c o r r}\right)$ and corrosion current density $\left(j_{\text {corr }}\right)$ values were determined by Tafel analysis from the anodic and cathodic branches of the polarization plots. Average values for these parameters are presented in Table 3. It must be noticed that untreated Zr5Ti and Zr25Ti exhibit dangerously low breakdown potentials in acidified Ringer's solution (cf. Figure 4A). This feature evidences that these materials are susceptible to the nucleation of localized corrosion. The addition of titanium to zirconium reduces the susceptibility of the later towards this form of corrosion, as indicated by the shift of the breakdown potentials to more positive values. This is in agreement with our previous reports on the corrosion behaviour of ZrTi alloys in conventional Ringer's solution $\mathrm{pH}=6.8$ $[25,30]$. However, the values encountered for jcorr and jpass are higher in acidic Ringer's solution. $\mathrm{Zr}$ corrodes in acidic solutions and the area of oxide stability lies between $\mathrm{pH} 3.5$ and 13 [32]. If passivation does not occur, Zr will react with the surrounding chemical species such as chloride and will be transformed into its ionic form [17].

The presence of chloride ions in acidic Ringer' solution $(\mathrm{pH}=3)$ is detrimental to the protection properties of $\mathrm{ZrO}_{2}$ surface film on Zr-based materials [17]. Figure 5 shows characteristic SEM micrographs of the untreated ZrTi samples retrieved from acidic Ringer's solution after anodic polarization tests that were terminated at $+1.0 \mathrm{VSCE}$. Inspection of the SEM images reveals the occurrence of localized corrosion at the surface of Zr5Ti and Zr25Ti alloys, whereas a rather uniform 
topography could be observed for the Zr45Ti alloy instead. Indeed, for the latter, the only defects observable in the micrographs correspond to small scratches remaining from the prior polishing of the surfaces. These results confirm the observations derived from the electrochemical tests.

Potentiodynamic polarization curves were also measured for the oxidized ZrTi alloys, and they are displayed in Figure 4B. In comparison with the corresponding curves determined from the untreated ZrTi alloys, the oxidized ZrTi alloys exhibited smaller corrosion currents, confirming the improved corrosion resistance of the treated alloys. Addition of titanium is observed to significantly contribute to a decrease in both the corrosion and the passivation currents (cf. Table 3). The SEM micrographs of the retrieved oxidized samples show the formation of cracks on the surface in the case of Zr5Ti and Zr25Ti alloys (see Figures 6A and B), whereas a uniform surface is offered by the Zr45Ti (Figure 6C).

In order to explore the insulating characteristics of the oxide films formed on the ZrTi alloys and their stability, scanning electrochemical microscopy (SECM) operated in the feedback mode was employed. Ferrocene-methanol was used as redox mediator through its oxidation to ferrocinium ion at the Pt microelectrode tip under diffusion-limited conditions by applying a potential value of +0.48 VSCE. Negative feedback behaviour should be expected if the oxide layers formed on the substrate would behave as barrier to electron transfer reactions, either ferrocene-methanol regeneration or metal dissolution from the metal substrate. This effect is better illustrated by recording the z-approach curves by progressively moving the tip towards the surface with the positioning motors of the SECM, while recording the faradaic current at the tip. The specimens were left unbiased in the acidified Ringer's solution. For the sake of normalization, the dimensionless tip current, $i / i_{l i m}$, was employed throughout. Normalized tip-substrate distances were obtained by dividing the absolute distance, $d$, by the diameter of the active Pt area of the tip microelectrode, $a$.

By approaching the substrate with the SECM tip, a progressively smaller volume of electrolyte is comprised in the volume gap between them. For the faradaic reaction to be maintained at the Pt tip, diffusion of the redox mediator from the electrolyte must occur. Due to increased hindrance to transport in the reduced amount of electrolyte available, the measured faradaic current must decrease steadily as the tip approaches an insulating surface. But the z-approach curves illustrated in Figure 7A measured for the untreated ZrTi alloys first exhibit an increase of the measured current as the tip moved into the nearfield range of the technique (i.e., normalized currents greater than one were measured). After describing a current maximum for normalized distances around 2-3, the current decreases and eventually negative feedback is observed for the smallest tip-substrate distances. The findings observed in the z-approach 
curves measured at $E_{O C P}$ of the alloys indicate that the oxide films show partial insulating characteristics as some regeneration of the redox mediator occurs at their surface, an effect already described for Ti-Mo and Ti-Ta alloys [33]. More insulating are the oxide layers formed on the alloys after thermal oxidation as illustrated by the corresponding $z$-approach curves displayed in Figure 7B.

The electrochemical activity of the oxide layers was further investigated by imaging a random surface of $250 \mu \mathrm{m} \times 250 \mu \mathrm{m}$ on the specimens. Figure 8 shows 3D images taken from the untreated samples immersed in acidified Ringer's solution. Weak positive feedback (e.g. electrochemical activity) was observed in regions of the Zr5Ti surface, as well as on the majority of the scanned surface in the case of Zr25Ti. Conversely, all the Zr45Ti remained electrochemically inactive as characterized by normalized currents smaller than 1 . The images do not show any topographic heterogeneities on the surface of the materials, and the observed variations in the measured currents can be ascribed to small unavoidable tilt of the samples.

SECM images of the oxidized samples are given in Figure 9. Negative feedback behaviour was observed in all the cases, corresponding to electrically insulating surfaces, in good agreement with the observations from the $z$-approach curves. Therefore, more compact and electrically insulating oxide films were produced on ZrTi alloys by thermal oxidation treatment in air.

\section{Conclusions}

The electrochemical behaviour of ZrTi alloys has been characterized in acidified Ringer's solution at $\mathrm{pH}=3$ in order to investigate their potential use as biomaterials. The development of passivity for all the ZrTi alloys was characterized from potentiodynamic polarization and EIS measurements. Electrochemical data show that the oxidized ZrTi alloys have better corrosion resistance than the untreated ZrTi alloys due to the formation of thicker inner oxide layers that act as dielectric barriers towards further electrodissolution of the underlying metals. Addition of titanium to zirconium assist the formation of more compact oxide layers, and at sufficiently high titanium contents (namely 45 at\%), the onset of localized pitting corrosion is suppressed.

\section{Acknowledgments}


This work was financially supported by the Romanian National Authority for Scientific Research (CNCS-UEFISCDI, Bucharest, Romania) within the research grant PN-II-ID-PCE-2011-3-0218, and by the Spanish Ministry of Economy and Competitiveness (MINECO, Madrid, Spain) jointly with the European Regional Development Fund (Brussels, Belgium) under grant CTQ2012-36787. The award of a Research Training Grant to J.I. by the Spanish Ministry of Education (Programa de Formación de Personal Investigador, Madrid, Spain) is greatly appreciated. Thanks are due to Zirom S.A. (Giurgiu, Romania) for kindly providing the ZrTi alloys used in this work.

\section{References}

1. B. Kasemo, Biological surface science, Surf. Sci. 500 (2002) 656-677.

2. M.P. Staiger, A.M. Pietak, J. Huadmei, G. Dias, Magnesium and its alloys as orthopedic biomaterials: A review, Biomaterials 27 (2006) 1728-1734.

3. M. Geetha, A.K. Singh, R. Asokamani, A.G. Gogia, Ti based biomaterials, the ultimate choice for orthopaedic implants - A review, Prog. Mater. Sci. 54 (2009) 397-425.

4. R. Bosco, J. van den Deuken, S. Leeuwenburgh, J. Jansen, Surface engineering for bone implants: A trend from passive to active surfaces, Coatings 2 (2012) 95-119.

5. R.M. Urban, J.J. Jacobs, M.G. Tomlinson, J. Gavrilovic, J. Black, M. Peoc'h, Dissemination of wear particles to the liver, spleen, and abdominal lymph nodes of patients with hip or knee replacement, J. Bone Joint Surg. A 82 (2000) 457-477.

6. I. Milošev, V. Antolič, A. Minovič, A. Cör, S. Herman, V. Pavlovčič, P. Campbell, Extensive metallosis and necrosis in failed prostheses with cemented titanium-alloy stems and ceramic heads, J. Bone Joint Surg. B 82 (2000) 352-357.

7. N.J. Hallab, S. Anderson, M. Caicedo, A. Brasherm, K. Mikecz, J.J. Jacobs, Effects of soluble metals on human peri-implant cells, J. Biomed. Mater. Res. A 74 (2005) 124-140.

8. H. Mutlu, E. Oktay, Characterization of 17-4 PH stainless steel foam for biomedical applications in simulated body fluid and artificial saliva environments, Mater. Sci. Eng. C 33 (2013) 1125-1131.

9. G.T. Burstein, C. Liu, R.M. Souto, S.P. Vines, Origins of pitting corrosion, Corros. Eng. Sci. Techn. 39 (2004) 25-30.

10. G.T. Burstein, R.M. Souto, Observations of localised instability of passive titanium in chloride solution, Electrochim. Acta 40 (1995) 1881-1888. 
11. R.M. Souto, G.T. Burstein, A preliminary investigation into the microscopic depassivation of passive titanium implant materials in vitro, J. Mater. Sci. Mater. Med. 7 (1996) 337-343.

12. G.T. Burstein, C. Liu, R.M. Souto, The effect of temperature on the nucleation of corrosion pits on titanium in Ringer's physiological solution, Biomaterials 26 (2005) 245-256.

13. M. Geetha, U.M. Kamachi, A.K. Gogia, R. Asokamani, R. Baldev, Influence of microstructure and alloying elements on corrosion behaviour of Ti-13Nb-13Zr alloy, Corros. Sci. 46 (2004) 877-892.

14. D.A. López, L. Durán, S.M. Cere, Electrochemical characterization of AISI 316L stainless steel in contact with simulated body fluid under infection conditions, J. Mater. Sci. Mater. Med. 19 (2008) 2137-2144.

15. R.J. Solar, in: Corrosion and degradation of implant materials, B.C. Syrett, A. Acharya (Eds.), STP 684, American Society for Testing and Materials, Philadelphia, PA (1979), p. 259.

16. P.I. Marshall, G.T. Burstein, The effects of $\mathrm{pH}$ on the repassivation of 304L stainless steel, Corros. Sci. 23 (1983) 1219-1228.

17. C.T. Kwok, P.K. Wong, H.C. Man, F.T. Cheng, Effect of $\mathrm{pH}$ on corrosion behavior of CuCrZr in solution without and with $\mathrm{NaCl}$, J. Nucl. Mater. 394 (2009) 52-62.

18. Y. Okazaki, E. Gotoh, Comparison of metal release from various metallic biomaterials in vitro, Biomaterials 26 (2005) 11-21.

19. F.X. Xie, X.B. He, S.L. Cao, X. Lu, X.H. Qu, Structural characterization and electrochemical behaviour of laser-sinterized porous Ti-10Mo alloy, Corrosion Science 67 (2013) 217-224.

20. ASM Handbook. Corrosion, Vol. 13, $9^{\text {th }}$ edn.; ASM International, Metals Park, 1987, p. 725.

21. P. Kovacs and J.A. Davidson, in: Medical applications of titanium and its alloys: The materials and biological issues, S.A. Brown and J.E. Lemons (Eds.); American Society for Testing and Materials, West Conshohocken, 1996, p. 163.

22. Y.F. Zheng, D. Liu, X.L. Liu, L. Li, Enhanced corrosion resistance of Zr coating on biomedical TiNi alloy prepared by plasma immersion ion implantation and deposition, Appl. Surf. Sci. 255 (2008) 512-514.

23. Y. Ikarashi, K. Toyoda, E. Kobayashi, H. Doi, T. Yoneyama, H. Hamanaka, T. Tsuchiya, Improved biocompatibility of titanium-zirconium (Ti-Zr) alloy: Tissue reaction and sensitization of $\mathrm{Ti}-\mathrm{Zr}$ alloy compared with pure Ti and Zr in rat implantation study, Mater. Trans. 46 (2005) 2260-2267.

24. H. M. Grandin, S. Berner, M. Dard, A review of titanium zirconium (TiZr) alloys for use in endosseous dental implants, Materials 5 (2012) 1348-1360. 
25. G. Bolat, J. Izquierdo, J.J. Santana, D. Mareci, R.M. Souto, Electrochemical characterization of ZrTi alloys for biomedical applications, Electrochim. Acta 88 (2013) 447-456.

26. E.A. Ferreira, N.T.C. Oliveira, S.R. Biaggio, P.A.P. Nascente, R.C. Rocha-Filho, N. Bocchi, XPS characterization of anodic oxides grown on biocompatible Ti-50Zr alloy in different acid electrolytes, Surf. Interf. Anal. 38 (2006) 417-421.

27. E.A. Ferreira, R.C. Rocha-Filho, S.R. Biaggio, N. Bocchi, Corrosion resistance of the Ti-50Zr at.\% alloy after anodization in different acidic electrolytes, Corros. Sci. 52 (2010) 4058-4063.

28. I. Vaquila, L.I. Vergara, M.C.G. Passeggi Jr, R.A. Vidal, J. Ferrón, Chemical reactions at surfaces: titanium oxidation, Surf. Coat. Technol 122 (1999) 67-71.

29. C. Delgado-Alvarado, P.A. Sundaram, Corrosion evaluation of Ti-48Al-2Cr-2Nb (at.\%) in Ringer's solution, Acta Biomater. 2 (2006) 701-708.

30. G. Bolat, J. Izquierdo, D. Mareci, D. Sutiman, R.M. Souto, Electrochemical characterization of ZrTi alloys for biomedical applications. Part 2. The effect of thermal oxidation, Electrochim. Acta 106 (2013) 432-439.

31. B. Yeum, Electrochemical impedance spectroscopy: Data analysis software; Echem Software, Ann Arbor, 2001.

32. D.A. Jones, Principles and prevention of corrosion, 2nd Edn.; Prentice-Hall, Upper Saddle River, 1996, p. 62-63.

33. G. Ciurescu, J. Izquierdo, J.J. Santana, D. Mareci, D. Sutiman, S. González, R.M. Souto, Characterization of the localized surface chemical activity of Ti-Mo and Ti-Ta alloys for biomedical applications using scanning electrochemical microscopy, Int. J. Electrochem. Sci. 7 (2012) 74047424. 

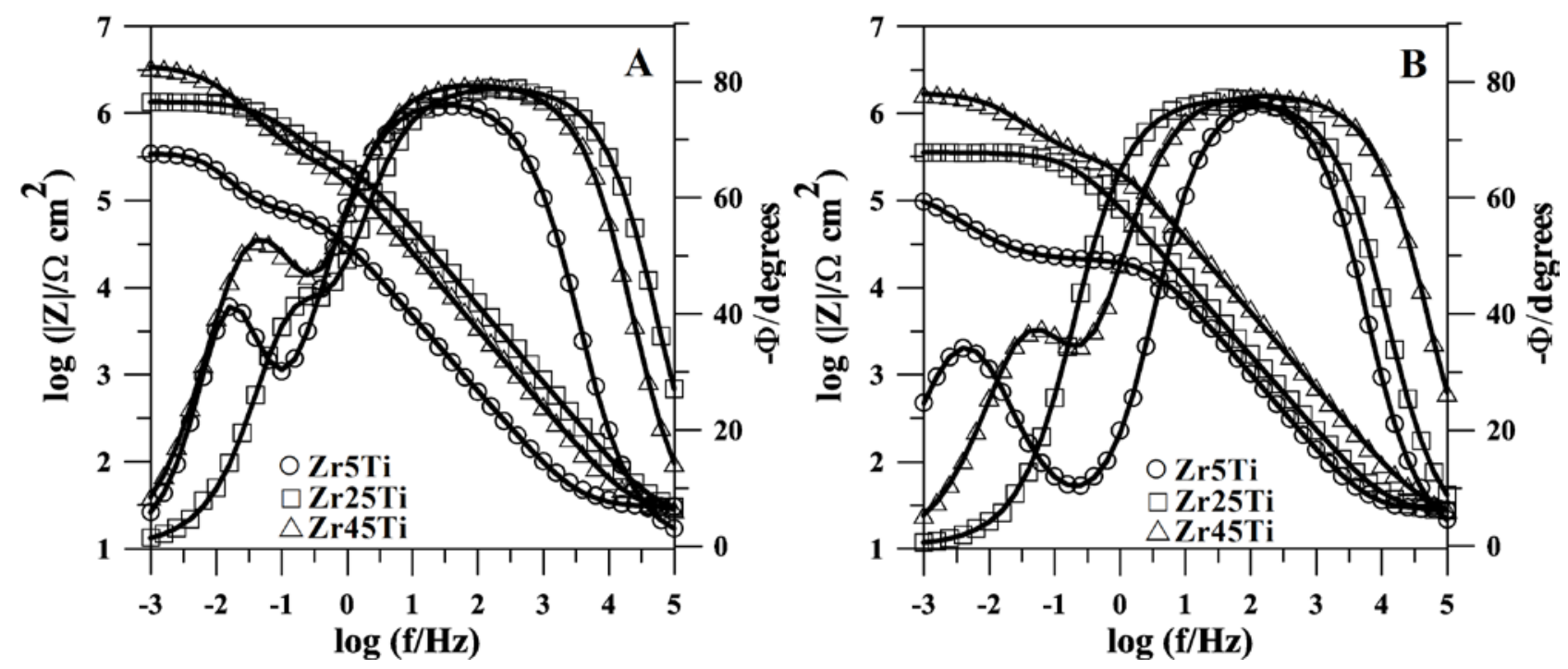

Figure 1. Measured (discrete points) and fitted (solid lines) impedance spectra for untreated ZrTi alloys recorded at their open circuit potentials during exposure to acidified Ringer's solution at $25{ }^{\circ} \mathrm{C}$ for: (A) 1 hour, and (B) 1 day.

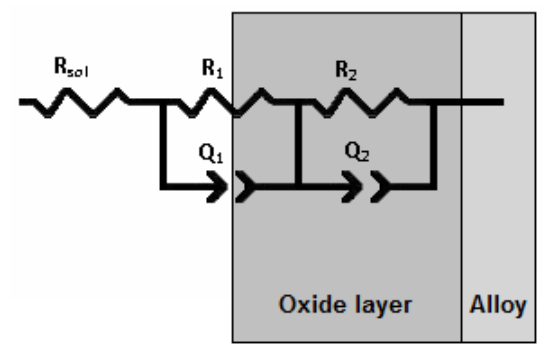

Figure 2. Equivalent circuit (EC) used for the interpretation of the impedance spectra.
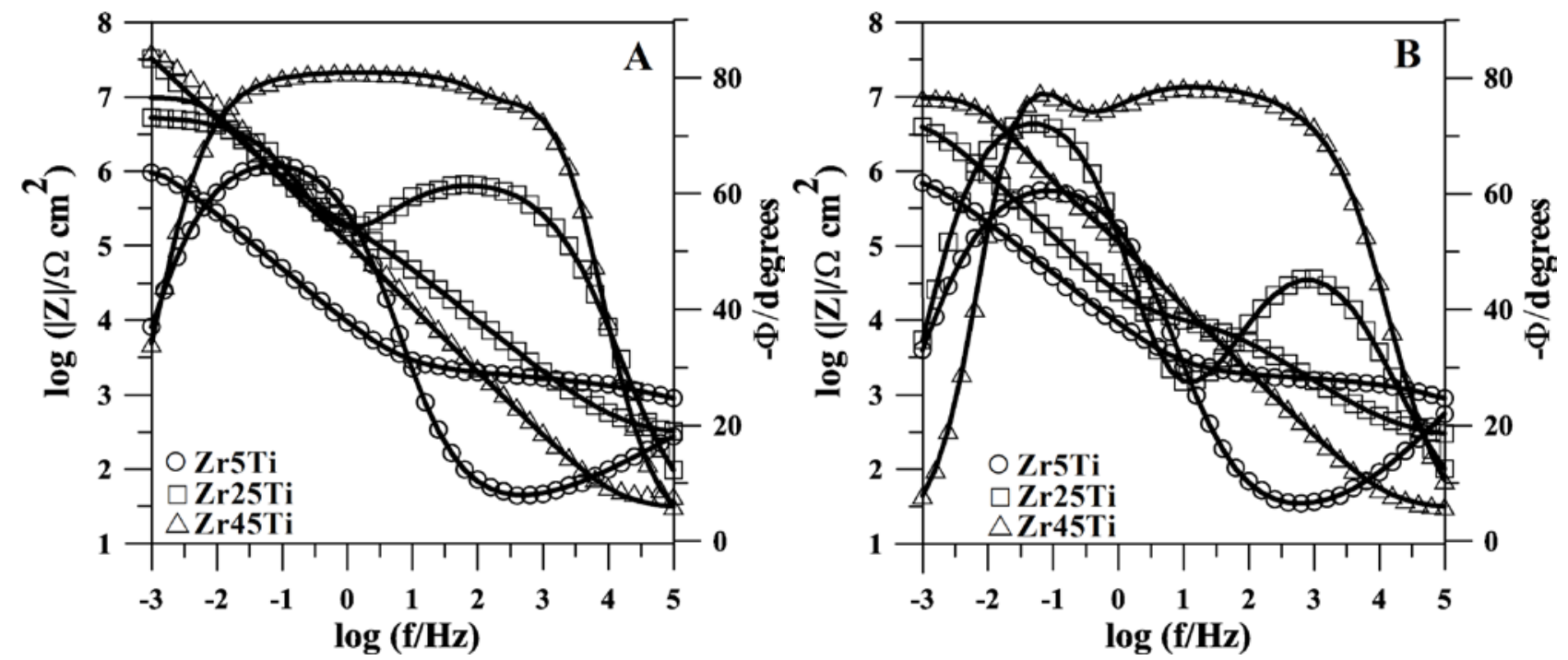

Figure 3. Measured (discrete points) and fitted (solid lines) impedance spectra for oxidized ZrTi alloys recorded at their open circuit potentials during exposure to acidified Ringer's solution at $25{ }^{\circ} \mathrm{C}$ for: (A) 1 hour, and (B) 1 day. 

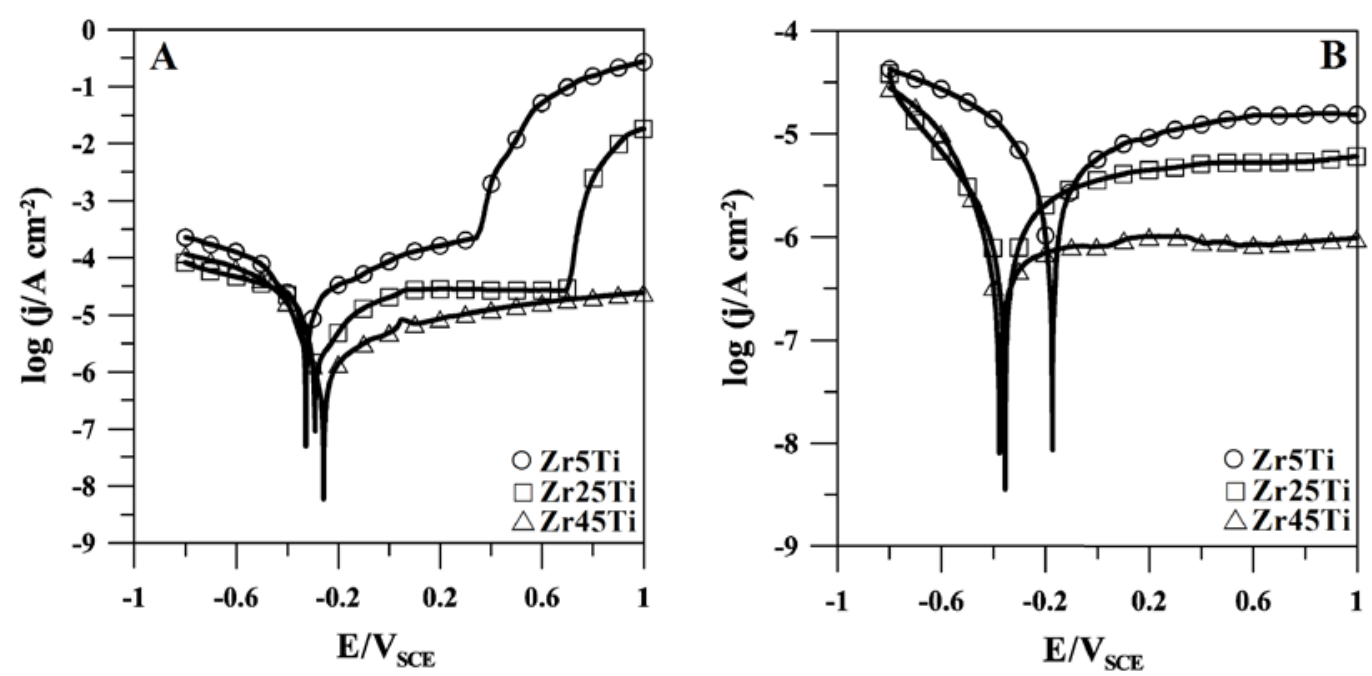

Figure 4. Potentiodynamic polarization curves for (A) untreated, and (B) oxidized ZrTi alloys immersed in acidified Ringer's solution at $25^{\circ} \mathrm{C}$. Scan rate: $0.5 \mathrm{mV} \mathrm{s}^{-1}$.
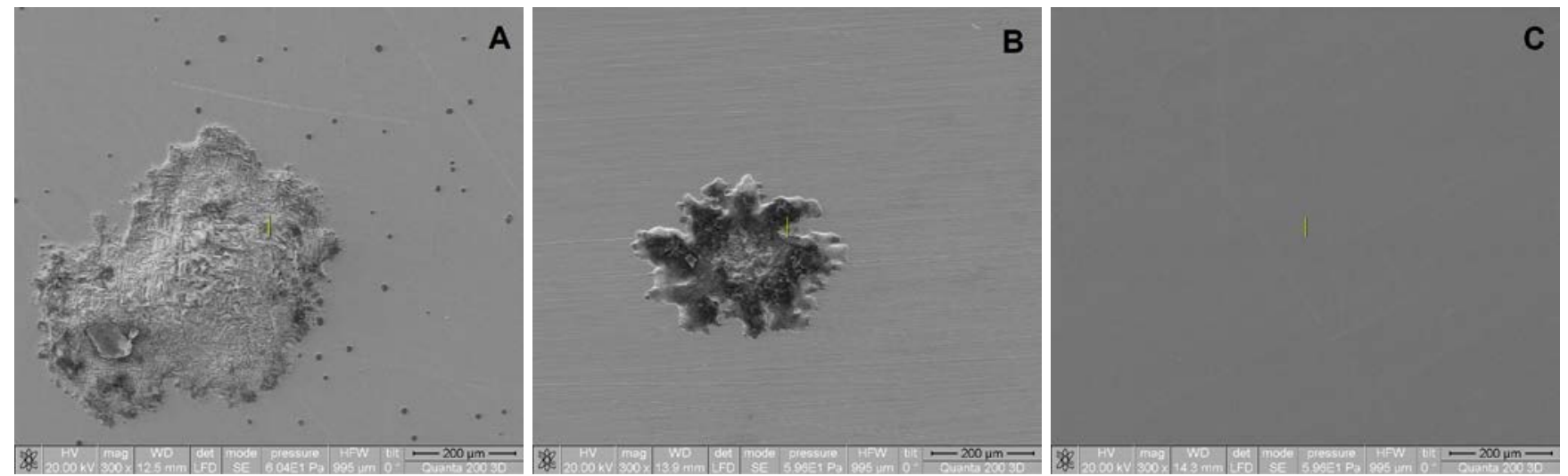

Figure 5. SEM images of the untreated $\mathrm{ZrTi}$ alloys retrieved at $+1.0 \mathrm{VSCE}$ from acidified Ringer's solution at $25{ }^{\circ} \mathrm{C}$ surface after recording the corresponding potentiodynamic polarization curve given in Figure 4A. (A) Zr5Ti, (B) Zr25Ti, and (C) Zr45Ti alloys.
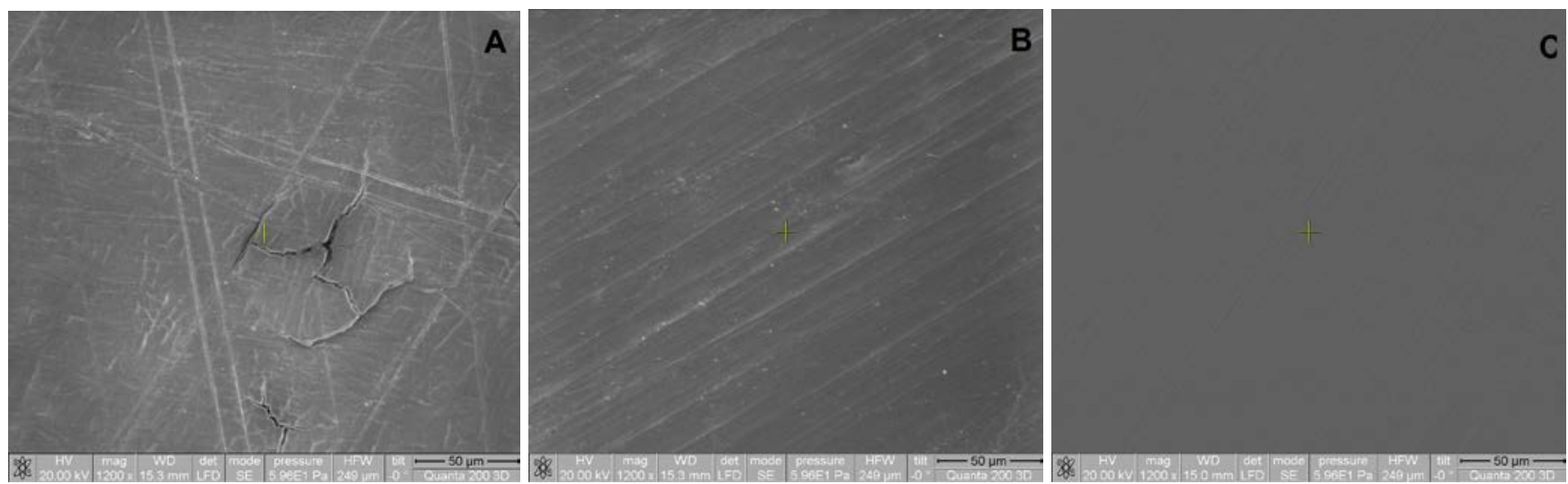

Figure 6. SEM images of the oxidized ZrTi alloys retrieved at +1.0 VSCE from acidified Ringer's solution at $25^{\circ} \mathrm{C}$ surface after recording the corresponding potentiodynamic polarization curve given in Figure 4B. (A) Zr5Ti, (B) Zr25Ti, and (C) Zr45Ti alloys. 

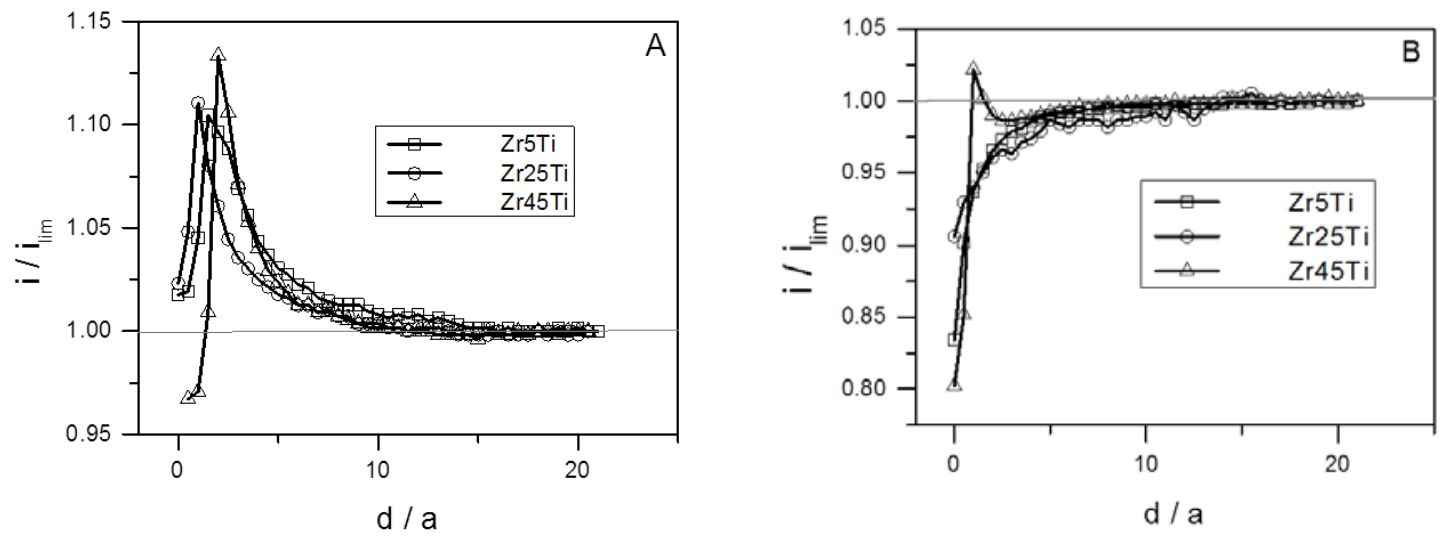

Figure 7. $z$-approach curves recorded by moving the SECM tip towards the surface of ZrTi alloys immersed in acidified Ringer's solution containing $0.5 \mathrm{mM}$ ferrocene-methanol. Tip potential: +0.48 VsCE; scan rate: $10 \mu \mathrm{m} \mathrm{s}^{-1}$; (A) untreated, and (B) oxidized TiZr alloys of the compositions given in the graphs. Samples were left unbiased at their corresponding EocP.

(A)

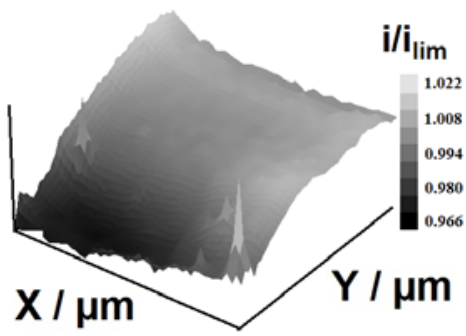

(B)

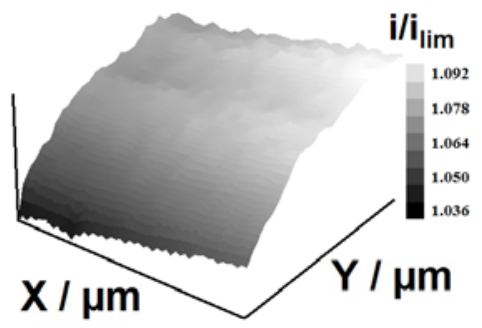

(C)

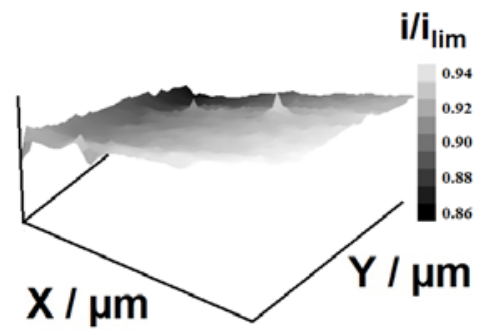

Figure 8. SECM images of untreated ZrTi alloys immersed in acidified Ringer's solution containing 0.5 $\mathrm{mM}$ ferrocene-methanol. Tip potential: +0.48 VsCE; scan rate: $30 \mu \mathrm{m} \mathrm{s}^{-1}$; (A) Zr5Ti, (B) Zr25Ti, and (C) Zr45Ti. Images represent an area of $250 \mu \mathrm{m} \times 250 \mu \mathrm{m}$. Samples were left unbiased at their corresponding EOCP.

(A)

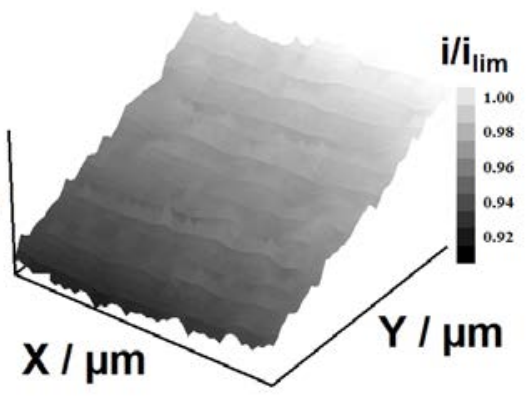

(B)

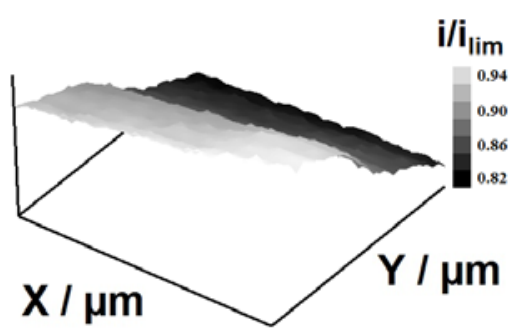

(C)

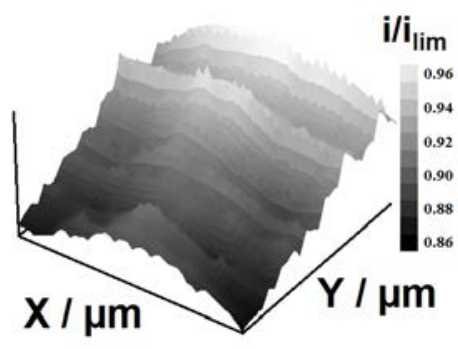

Figure 9. SECM images of oxidized ZrTi alloys immersed in acidified Ringer's solution containing 0.5

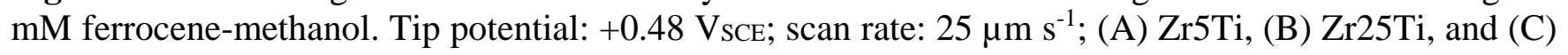
Zr45Ti. Images represent an area of $250 \mu \mathrm{m} \times 250 \mu \mathrm{m}$. Samples were left unbiased at their corresponding ЕосP. 